\title{
GeNETIC VARIABILITY OF TRIATOMA RUBROVARIA (REDUVIIDAE: TRIATOMINAE) FROM BRAZIL, ARGENTINA AND URUGUAY AS REVEALED BY TWO DIFFERENT MOLECULAR MARKERS
}

\author{
PACHECO R.S.*, ALMEIDA C.E.**, KLISIOWICZ D.R.***, COSTA J.**, PIRES M.Q.*, PANZERA F. ***********, BAR \\ M.E.******, MAS-COMA S.*** \& BARGUES M.D.***
}

\section{Summary:}

Randomly amplified polymorphic DNA (RAPD) and nuclear ribosomal DNA sequence analyses were used to assess the genetic population structure of the South American triatomine species Triatoma rubrovaria throughout its geographical distribution. To investigate the genetic variability at both intraspecific and intrapopulational levels the RAPD profiles and the nucleotide sequences of the rDNA intergenic spacers, ITS- 1 and ITS-2, were analysed and compared. The phenetic analysis based on RAPD profiles show three distinct clusters diverging by similarity coefficients ranging from 0.62 to 0.96 . The ITS- 1 and ITS-2 sequence variability detected may be considered very high, suggesting reproductive isolation between populations. A total of seven composite haplotypes $(\mathrm{CH})$ were found, among which three are specific for Brazil, other three for Uruguay, and the last one common for the three countries studied. The population studied in Argentina does not represent an independent $\mathrm{CH}$. Sequence analyses proved that the five populations studied are easily differentiable and that there is heterogeneity within each one. True mutations and indels are the responsible of sequence differences between haplotypes and populations, suggesting that divergence intraspecific variability detected may underlie the known plasticity of $T$. rubrovaria, making it a potential intradomiciliary invader and consequently an appropriate vector for Chagas disease transmission. Therefore, this triatomine species must be continuously monitored throughout.

KEY WORDS : Triatoma rubrovaria, RAPD, ribosomal DNA, population genetics, South America. processes may presently go on within this species. The large

Résumé : VARIABILITÉ génÉTIQUe des POPUlations de Triatoma RUbrovaria (ReduviIdae : Triatominae) Du Brésil, D'Argentine et D'URUGUAY, ÉTUDIÉE PAR DEUX MARQUEURS MOLÉCULAIRES DIFFÉRENTS

L'amplification aléatoire d'ADN polymorphe (RAPD) et l'analyse des séquences de l'ADN ribosomal nucléaire ont été utilisées pour évaluer la structure génétique de populations de Triatoma rubrovaria, une espèce de triatominés de l'Amérique du Sud, selon leur distribution géographique. La variabilité génétique a été investiguée aux niveaux intraspécifique et intrapopulationnel, en utilisant l'analyse et la comparaison des RAPD et des séquences nucléotidiques complètes des espaceurs intergéniques de l'ADN ribosomial, ITS-1 et ITS-2. L'analyse phénétique basée sur des profils RAPD montre trois groupes distincts qui divergent par des coefficients de similarité allant de 0.62 à 0.96. La variabilité des séquences de l'ITS-1 et de l'ITS-2 observée est considerée comme trés elevée, suggérant un isolement reprodif entre les populations. Sept haplotypes composés $(\mathrm{CH})$ ont été trouvés, parmi lesquels trois sont spécifiques du Brésil, trois de l'Uruguay, le dernier étant commun aux trois pays étudiés. La population de l'Argentine ne présente pas de $\mathrm{CH}$ indépendent. Les analyses des séquences prouvent que les cinq populations étudiées sont facilement différenciables, bien qu'il existe une hétérogénéité au sein de chacune d'elles. Des vraies mutations et des indels sont les responsables des différences d'ordre entre les haplotypes et les populations, suggérant que les processus de divergence puissent actuellement continuer au sein de cette espèce. La grande variabilité intraspécifique observée souligne la plasticité connue de T. rubrovaria, en faisant un envahisseur potentiel du domicile et par conséquent un vecteur approprié pour la transmission de la maladie de Chagas. Cette espèce de triatominés doit donc être continuellement contrôlée.

MOTS CLÉS : Triatoma rubrovaria, RAPD, ADN ribosomal, génétique des populations, Amérique du Sud.

\section{INTRODUCTION}

* Departamento de bioquímica e biología molecular, Instituto Oswaldo Cruz-FIOCRUZ, Rio de Janeiro, Brazil.

** Departamento de entomologia, Instituto Oswaldo Cruz-FIOCRUZ, Rio de Janeiro, Brazil.

**: Departamento de parasitología, Facultad de farmacia, Universidad de Valencia, Spain.

**:*** Facultad de ciencias, Universidad de la República, Montevideo, Uruguay.

***:**: CISEI, Instituto nacional de salud pública, Cuernavaca, Morelos, Mexico.

**:*:** Facultad de ciencias exactas y naturales y agrimensura, Universidad nacional del Nordeste, Corrientes, Argentina.

Correspondence: Maria Dolores Bargues, Departamento de parasitologia, Facultad de farmacia, Universidad de Valencia, Av. Vicent Andres Estelles s/n, 46100 Burjassot-Valencia, Spain.

Tel.: 34-96-386-42-98 - Fax: 34-96-386-47-69.

E-mail: M.D.Bargues@uv.es
1 Triatoma rubrovaria (Blanchard in Blanchard et Brullé 1843), a member of the "infestans" subgroup, is a potential vector of Chagas disease. Its geographic distribution includes Southern Brazil, mainly the States of Rio Grande do Sul and Paraná, part of North-eastern Argentina and Uruguay (Dujardin et al., 2000). This species is considered a generalistic insect that feeds on a variety of vertebrate and invertebrate hosts (Salvatella et al., 1995). Biological aspects such as feeding, defaecation behaviour, resistance to starvation and life cycle make T. rubrovaria a potential vector for Trypanosoma cruzi transmission (Bar 
et al., 2003; Almeida et al., 2005). In fact, such species has already been found naturally infected with Trypanosoma cruzi in the three countries (Salvatella et al., 1995). Previous studies have demonstrated that in the State of Rio Grande do Sul, in Brazil, two genetically distinct populations of T. rubrovaria are present (Almeida et al., 2002; Pacheco et al., 2003).

Due to the epidemiological importance of T. rubrovaria as a potential vector of Chagas disease, the present work aims to genetically characterize the population structure of specimens from Brazil, Argentina and Uruguay in the way to evaluate its spreading capacity and human influence on its population structure. RAPD analyses and sequencing of the complete intergenic region of the nuclear rDNA, including the spacers ITS1 and ITS-2, are used to compare T. rubrovaria populations from the three South American countries.

\section{MATERIALS AND METHODS}

\section{TRIATOMA RUBROVARIA SPECIMENS}

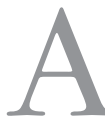
total of 12 adult specimens were captured in the Municipalities of Santana do Livramento (L07, L09, L10, L11, L12, L19) and Santiago (S01, S03, S13, S14, S25, S26), State of Rio Grande do Sul, RS, Brazil. From Argentina a total of nine adult specimens (Co01, Co02, Co03, Co04, Co05, Co06, Co07, Co08, Co09) were captured in an area of natural rock piles distant $37 \mathrm{~km}$ from the Municipality of Mercedes, Corrientes (Bar et al., 2003; Damborsky et al., 2005). From Uruguay a total of four adult specimens from the Department of Salto (Sal13, Sal15) and Río Negro (RN16, RN17)

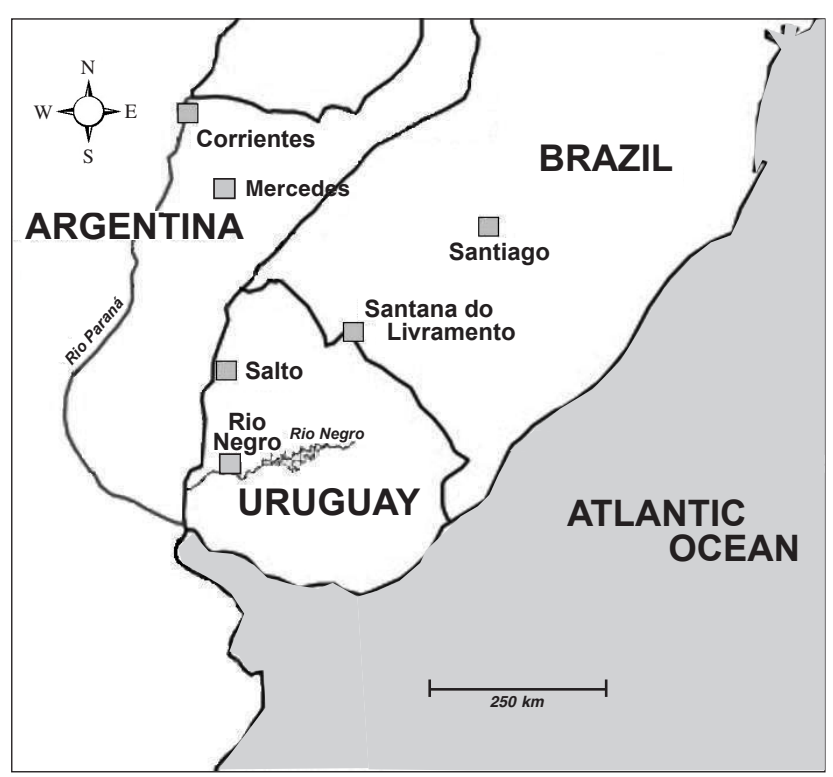

Fig. 1. - Map showing the localities of Triatoma rubrovaria specimens captured in the three South American countries. were analysed (Fig. 1). All insects were taxonomically identified as T. rubrovaria using the keys of Lent and Wygodzinsky (1979).

\section{RAPD AND NUMERICAL (PHENETIC) ANALYSES}

23 out of the 25 specimens of T. rubrovaria (two from Brazil were lost during DNA extraction procedures) were studied. DNA was extracted according to the protocol previously described (Pacheco et al., 2003). As negative control and outgroup, DNA from Triatoma sordida was included in each gel.

Phenetic analyses were carried out using the Simplematching coefficient of similarity to determine the proportion of mismatched bands between pairs of T. rubrovaria. The similarity matrix was transformed into a phenogram using the UPGMA algorithm and the NTSys software programme (Exeter software, Setanker, NY).

\section{RDNA SEQUENCE ANALYSES}

For DNA extraction, one or two legs fixed in ethanol $70 \%$ from each specimen were used and processed individually, as previously described (Marcilla et al., 2001) and following the methods outlined before (Bargues et al., 2006). Sequencing was performed on both strands by the dideoxy chain-termination method, and with the Taq dye-terminator chemistry kit for $\mathrm{ABI}$ 3730 and ABI 3700 capillary system (Perkin Elmer, Foster City, CA, USA), using PCR primers. Sequences were aligned using CLUSTAL-W version 1.8 and assembly was made with the Staden Package version 1.5. The haplotype terminology used in the present paper follows the nomenclature for composite haplotyping $(\mathrm{CH})$ recently proposed by Bargues et al. (2006). Phylogenies were inferred from rDNA ITS-1, 5.8S, ITS-2 region using maximum-likelihood (ML) estimates with PAUP v.4.0b10 (Swofford, 2002). ML parameters were optimized using the hierarchical Lihelihood Ratio Test (hLRTs) implemented in Modeltest 3.7 (Posada \& Crandall, 1998). Starting branch lengths were obtained using least-squares method with ML distances. To provide an assessment of the reliability of the nodes of the trees, a quartet puzzling analysis was employed with 1000 puzzling steps and 1000 Heuristic Bootstrap replicates.

\section{RESULTS}

\section{RAPD ANALYSES}

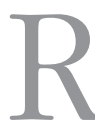
APD analyses revealed genotypic heterogeneity at intra and inter-populational levels in T. rubrovaria specimens from the three South American countries. Genetic diversity was observed in the number and size of the fragments amplified after PCR 
using six different primers. The presence of conserved bands was detected in all populations. Among the six primers tested none was found to be sufficiently specific as to discriminate a particular population. Each specimen showed a different RAPD profile (Table I). Profiles generated by the primers 4,5 and 6 produced a total of 90 characters limited to bands ranging from 300 to 1,600 base pars (bp), of which 27 bands were shared among the populations (Table I). For the phenetic analyses, the three-primer-consensus profiles were converted into a matrix of binary data, with 0 indica- ting the absence of a particular character (band) and 1 its presence. The Simple-matching Similarity indices were calculated using the UPGMA algorithm by comparing each pair of specimens.

The phenogram obtained placed the 23 specimens into three great clusters diverging by similarity coefficients ranging from 0.62 to 0.96 (Fig. 2; Table I). The first cluster only comprises specimens from Santiago, RS, Brazil (S01, S03, S14, S25 and S26), with two specimens (S03 and S14) appearing very closely related because of a $96 \%$ character sharing. The second phe-

\begin{tabular}{|c|c|c|c|c|}
\hline $\begin{array}{l}\text { Insect } \\
\text { code }\end{array}$ & $\begin{array}{c}\text { Geographical } \\
\text { origin }\end{array}$ & Shared bands & $\begin{array}{l}\text { Phenetic } \\
\text { cluster }\end{array}$ & $\begin{array}{l}\text { Composite } \\
\text { haplotype }\end{array}$ \\
\hline S01 & Santiago, Brazil & 1.2.5.6.8.9.10.12.13.14.16.17.18.19.29.21.22.23.25.27 & I & $\mathrm{CH} 3 \mathrm{C}$ \\
\hline S03 & Santiago, Brazil & 1.2.4.5.6.8.9.10.11.12.13.16.17.18.19.20.21.22.23.25.27 & I & $\mathrm{CH} 3 \mathrm{C}$ \\
\hline S14 & Santiago, Brazil & 1.2.4.5.6.8.9.10.11.12.13.15.16.17.18.19.20.21.22.23.25.27 & I & $\mathrm{CH} 3 \mathrm{C}$ \\
\hline S25 & Santiago, Brazil & 1.2.4.5.6.8.9.10.13.15.16.17.18.19.20.21.22.23.25.26 & I & $\mathrm{CH} 3 \mathrm{C}$ \\
\hline S26 & Santiago, Brazil & 1.2.4.5.8.9.10.11.13.14.15.16.17.18.19.20.21.23.25.26 & I & $\mathrm{CH} 3 \mathrm{D}$ \\
\hline L07 & Livramento, Brazil & 1.2 .3 .4 .5 .6 .8 .10 .12 .13 .14 .15 .16 .17 .18 .19 .20 .21 .24 .26 & II & $\mathrm{CH} 2 \mathrm{~A}$ \\
\hline L12 & Livramento, Brazil & $1.2 .4 \cdot 6.8 \cdot 10.12 .13 .14 .15 \cdot 16.17 .18 .19 \cdot 20.21 .24 .26$ & II & $\mathrm{CH} 1 \mathrm{~A}$ \\
\hline L10 & Livramento, Brazil & 1.2.5.6.8.10.12.13.14.15.16.17.18.19.21.24.26 & II & $\mathrm{CH} 1 \mathrm{~A}$ \\
\hline RN17 & Rio Negro, Uruguay & 2.5 .6 .8 .10 .12 .13 .14 .15 .16 .17 .18 .19 .20 .24 .26 & II & $\mathrm{CH} 2 \mathrm{~B}$ \\
\hline L11 & Livramento, Brazil & 1.2.4.6.8.9.10.12.13.15.16.17.18.19.20.21.24 & II & $\mathrm{CH} 1 \mathrm{~A}$ \\
\hline L19 & Livramento, Brazil & 1.2.3.4.5.6.8.9.10.11.12.13.15.16.17.18.19.20.21.24.26 & II & $\mathrm{CH} 1 \mathrm{~A}$ \\
\hline Sal13 & Salto, Uruguay & 2.3.5.6.8.9.10.12.13.15.16.17.18.19.20.22.25 & II & $\mathrm{CH} 1 \mathrm{~A}$ \\
\hline Sal15 & Salto, Uruguay & 2.4.5.6.8.9.12.13.14.15.16.17.18.19.20.25 & II & $\mathrm{CH} 1 \mathrm{~B}$ \\
\hline RN16 & Rio Negro, Uruguay & 2.5.6.7.10.12.13.14.15.16.17.18.19.20.25.26 & II & $\mathrm{CH} 4 \mathrm{~B}$ \\
\hline $\mathrm{Co} 01$ & Corrientes, Argentina & 1.2.4.5.6.7.10.13.14.15.16.18.19.20.22.24 & III & $\mathrm{CH} 1 \mathrm{~A}$ \\
\hline $\mathrm{Co} 02$ & Corrientes, Argentina & 1.2.4.6.7.10.11.13.14.15.16.17.18.19.20.21.22.25 & III & $\mathrm{CH} 1 \mathrm{~A}$ \\
\hline $\mathrm{Co} 03$ & Corrientes, Argentina & $1.2 .4 .7 .10 .11 .13 .14 .15 \cdot 16.17 .18 .19 \cdot 20.21 .22 .25$ & III & $\mathrm{CH} 1 \mathrm{~A}$ \\
\hline $\mathrm{Co} 05$ & Corrientes, Argentina & 1.2 .4 .6 .7 .10 .11 .13 .14 .15 .17 .18 .19 .20 .21 .24 .25 & III & $\mathrm{CH} 1 \mathrm{~A}$ \\
\hline $\mathrm{Co} 06$ & Corrientes, Argentina & 1.2 .3 .4 .7 .10 .11 .13 .14 .15 .16 .17 .18 .19 .20 .21 .24 .26 & III & $\mathrm{CH} 1 \mathrm{~A}$ \\
\hline $\mathrm{Co} 09$ & Corrientes, Argentina & $1.2 .4 .5 .7 .9 .10 .11 .13 .14 .15 .17 .19 \cdot 20.21 .22 .24 .26$ & III & $\mathrm{CH} 1 \mathrm{~A}$ \\
\hline $\mathrm{Co08}$ & Corrientes, Argentina & 1.2.4.5.7.10.11.13.14.15.17.18.19.20.21.22.24 & III & $\mathrm{CH} 1 \mathrm{~A}$ \\
\hline $\mathrm{Co} 04$ & Corrientes, Argentina & 1.2.4.5.6.7.10.11.13.14.15.17.18.19.20.21.22.25.26 & III & $\mathrm{CH} 1 \mathrm{~A}$ \\
\hline $\mathrm{CoO} 7$ & Corrientes, Argentina & 2.3 .4 .7 .8 .10 .11 .12 .15 .17 .18 .19 .20 .21 .22 .24 .26 & III & $\mathrm{CH} 1 \mathrm{~A}$ \\
\hline
\end{tabular}

Table I. - Electromorphs (shared bands) observed after amplification with the three RAPD primers, the phenetic clusters and respective haplotypes obtained among the Triatoma rubrovaria populations analysed.

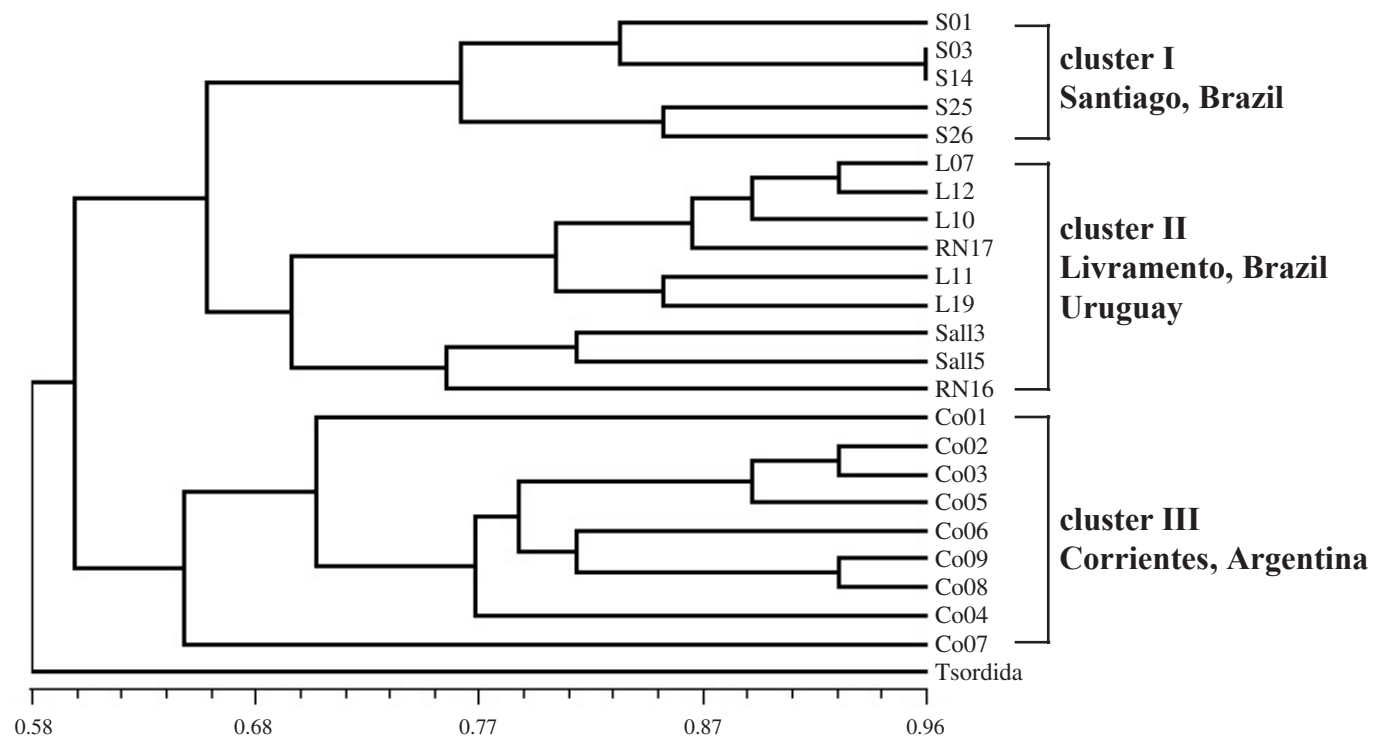

Fig. 2. - RAPD-consensus phenetic dendrogram of the triatomine specimens using the Simple Matching Coefficient of similarity. 
netic group was formed by specimens of Santana do Livramento, RS, Brazil, a locality close to the Uruguay border, and by specimens from Uruguay. Within this cluster, a sub-group composed by three specimens from Uruguay (Sal13, Sal15 and RN16) appears. Interestingly, a Rio Negro specimen (RN17) clusters together with specimens from Livramento, RS, Brazil (L07, L12 and L10). The third great cluster appears composed by the nine specimens from Corrientes, Argentina, including two well-diverging specimens (Co01 and Co07) displaying similarity coefficients of 0.72 and 0.65 , respectively (Fig. 2 ).

\section{RDNA SEQUENCE ANALYSES}

A total of seven haplotypes for the complete intergenic region analysed were detected in the populations studied. Tru-CH1A is present in Santana do Livramento (five individuals: L09, L10, L11, L12, L19), Corrientes (nine individuals: Co01 to Co09) and Salto (one individual: Sal13). Tru-CH1B, Tru-CH2A and Tru-CH2B are present in one individual from each Salto (Sal15), Santana do Livramento (L07) and Río Negro (RN17), respectively. Tru-CH3C is present in five individuals from Santiago (S01, S03, S13, S14, S25) and Tru-CH3D and Tru-CH4B are present in only one individual from each Santiago (S26) and Rio Negro (RN16), respectively (Table I). When haplotype presence/absence is analysed by countries, a total of four haplotypes are present in Brazil, (Tru-CH1A, Tru-CH2A, Tru-CH3C and Tru-CH3D), four haplotypes in Uruguay (Tru-CH1A, Tru-CH1B, Tru-CH2B and Tru-CH4B), and only one in Argentina (Tru-CH1A). The only haplotype simultaneously present in the three countries analysed is TruCH1A. The other six previously mentioned haplotypes could be considered as specific, three for Brazil and another different three for Uruguay (Table II).

The seven haplotype sequences have been deposited in the EMBL, GenBank and DDBJ databases, where they are available under the following accession numbers: Tru-CH1A = AJ557258, Tru-CH2A = AJ557259, Tru$\mathrm{CH} 3 \mathrm{C}=\mathrm{AJ} 557260$, Tru-CH3D $=\mathrm{AJ} 557261$, Tru-CH1B $=$ AM259052, Tru-CH2B = AM259053, and Tru-CH4B = AM259054.

The complete alignment of the seven haplotype sequences was 1,377 bp-long, showing a genetic divergence of $1.31 \%$. Nucleotide length and AT content of both spacer sequences and $5.8 \mathrm{~S}$ gene of all populations studied are noted in Table II. Concerning the ITS-1, four haplotypes were detected. These haplotypes are TruA, B, C and D and are distributed as follows: Tru-A is the most abundant and present in Brazil (Santana do Livramento), Argentina (Corrientes) and Uruguay (Salto); Tru-B is exclusive for Uruguay (Salto and Río Negro), and Tru-C and Tru-D are both exclusive for Brazil (Santiago). In the 730-bp-long alignment inclu- ding the four different ITS-1 haplotypes, nine nucleotide differences $(1.23 \%)$ appeared, of which three $(0.41 \%)$ were mutations, including two transitions (ts) and one transversion (tv), plus six (0.82 \%) insertions/ deletions (indels). Sequence repeats were detected and included a minisatellite of $31 \mathrm{bp}$ tandemly repeated two times between positions 292 and 356 of the haplotype total sequence alignment. At the level of ITS-2, four different haplotypes were detected too. These haplotypes are Tru-1, 2, 3 and 4 and are distributed as follows: Tru-1 is present in Brazil (Santana do Livramento), Argentina (Corrientes) and Uruguay (Salto); Tru-2 is present in Brazil (Santana do Livramento) and Uruguay (Río Negro), and Tru-4 is exclusive for Uruguay (Río Negro). A total of nine nucleotide differences were detected in the 492-bp-long alignment, including two ts $(0.41 \%)$ and seven indels $(1.42 \%)$, representing a $1.83 \%$ sequence divergence. The length of the ITS-2 also differs between populations, being only four and one base shorter in specimens from Rio Negro (487 bp) and Santiago (490 bp), respectively, than in specimens from Santana do Livramento, Salto and Río Negro (491 bp). In the ITS-2 sequence, the presence of the interrupted microsatellite $(\mathrm{AT})_{5-6}$ TTTTT $(\mathrm{AT})_{1}$ AA $(\mathrm{AT})_{7}$ was detected in all individuals and populations studied.

Phylogenetic analyses were performed including the seven T. rubrovaria $\mathrm{CH}$ and $T$. sordida (AJ576063) as outgroup. The ML model best fitting the data set was HKY85 + I using the ts/tv ratio of 2.0314. The resulting phylogeny $(-\operatorname{Ln}=2089.0427)$ confirm the separation of haplotypes Tru-CH3C and Tru-CH3D from Santiago, Brazil from the rest of the haplotypes with a 96 and 67 of puzzle and bootstrap values respectivley. A relatively low support values appear in the two clades comprising: a) the two haplotypes of T. rubrovaria from Rio Negro (Uruguay) and; b) haplotypes from Livramento (Brazil), Salto (Uruguay) and Corrientes (Argentina) (Fig. 3).

\section{DISCUSSION}

T $\mathrm{n}$ the present study, the consensus phenogram based on RAPD profiles reveals an unequivocal discrimination between two geographically distinct T. rubrovaria populations (Santiago in Brazil and Corrientes in Argentina). In addition, both populations appear to be geographically structured, which may suggest a founder effect. All suggests that the geographic distance between populations is an important factor determining its genetic structure, as already detected in Triatoma infestans (Dujardin et al., 1998; Bargues et al., 2006). On the other hand, the second phenetic cluster of the phenogram includes specimens geographically less distant despite proceeding from different 


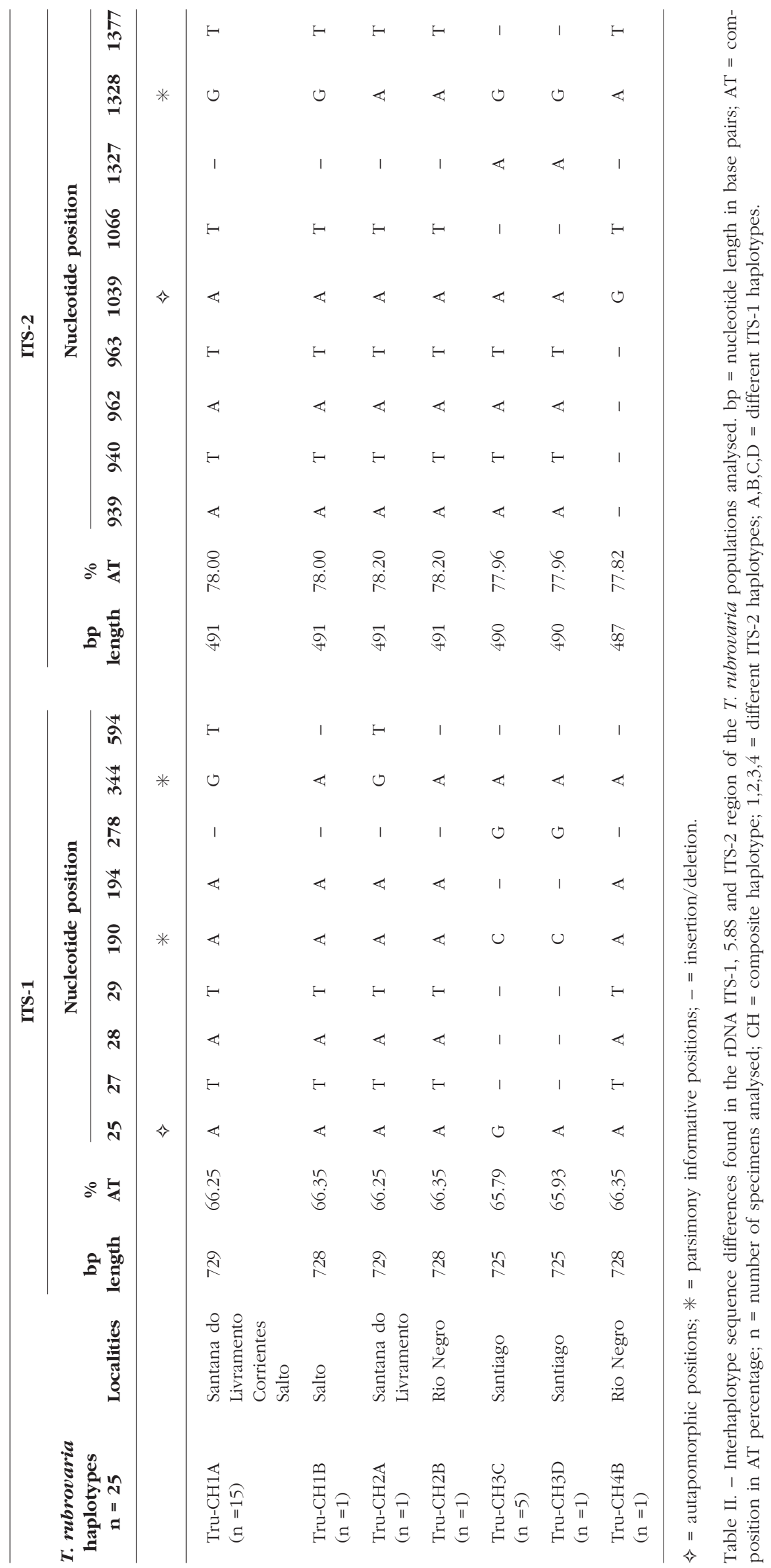




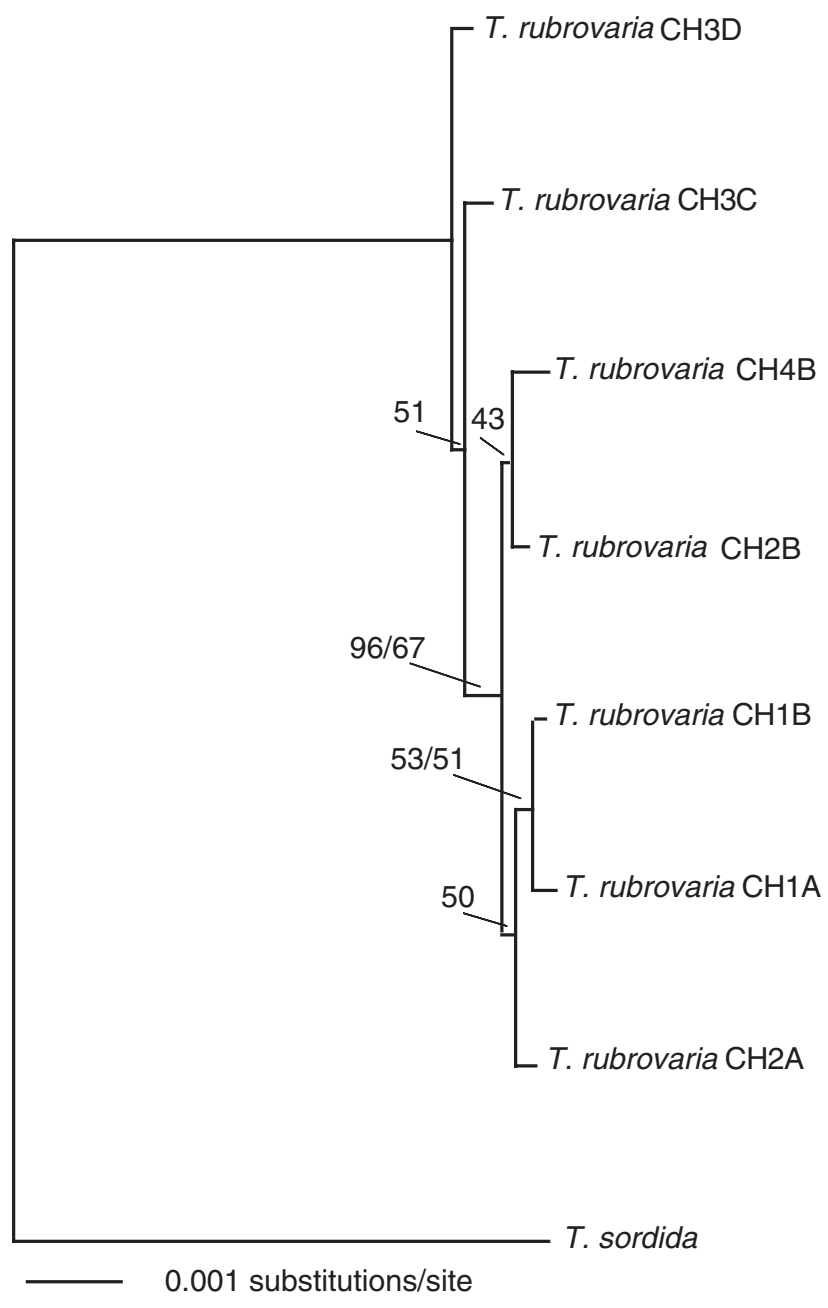

Fig. 3. - Phylogenetic tree of T. rubrovaria haplotypes, based on complete sequences of rDNA ITS-1, $5.8 \mathrm{~S}$ and ITS-2, derived from the maximum likelihood (ML HKY85+I) model using Triatoma sordida as outgroup. Numbers represent the percentage of 1,000 puzzling/bootstrap replicates. Scale bar indicates the number of substitutions per sequence position.

countries. No genetic-geographic association was found suggesting a dispersal capability and reshuffling of the haplotypes.

Concerning ITSs, and taking into account the capacity of ITS-1 and ITS-2 sequences to differentiate species, subspecies, hybrids and populations in Triatominae (Bargues et al., 2002, 2006; Marcilla et al., 2001, 2002; Pacheco et al., 2003), several conclusions can be reached: $a$ ) all individuals studied belong to the same species T. rubrovaria; $b$ ) the individuals analysed from the Brazilian localities of Santana do Livramento and Santiago belong to two clearly differentiable populations; c) the populations from Salto and Río Negro in Uruguay differ between them in three mutations and five indels, showing a genetic intra-populational variety; d) only one individual from Salto (Sal13) shows the same haplotype (Tru-CH1A) as the other five individuals from Santana do Livramento in Brazil and nine individuals from Corrientes, Argentina; $e$ ) three haplotypes (Tru-CH1B, Tru-CH2B, Tru-CH4B) are exclusive for Uruguay populations and other three are exclusives for Brazil populations (Tru-CH2A, Tru-CH3C, Tru-CH3D); f) there are only one haplotype (Tru-CH1A) simultaneously present in Brazil, Argentina and Uruguay, it appears to be the most frequent one (detected in 15 of 25 specimens analysed); $g$ ) in Corrientes, Argentina, all individuals analysed present the same haplotype (Tru-CH1A), without intra-populational variety.

Of the total of 18 nucleotide differences detected in the 1377-bp-long alignment of the seven different sequences of the ITS-1, $5.8 \mathrm{~S}$ and ITS-2 rDNA region, the majority (13) are indels and only five are true mutations, providing intra-populational differentiation. This suggests evolving divergence processes presently going on within the species in question (Pacheco et al., 2003). Phylogenetic analyses confirm the separation of haplotype Tru-CH3C and Tru-CH3D, mainly present in Santiago, Brazil, from the rest of the haplotypes.

Four haplotypes have been detected for each of both spacers. Intraspecific nucleotide differences appears to be identical in ITS- 1 and ITS- 2 concerning both substitutions and indels, although the nucleotide divergence is higher in ITS-2 (1.83\%) than in ITS-1 (1.23\%) because of their different length. These results are in agreement with the molecular clock dating proposed for triatomines, according to which ITS-1 evolves 1.122.60 times faster than ITS-2 (Bargues et al., 2000, 2006). Without considering indels because of their weight less than that of mutations, the number of ts and tv in ITS- 1 and ITS- 2 enables population differentiation. In T. rubrovaria from Brazil, Argentina and Uruguay, neither minisatellites nor microsatellites in both spacers discriminate the different populations.

According to the results obtained, the rDNA intergenic region appears to be a good marker for the analysis of the heterogeneity of $T$. rubrovaria populations. RAPD analyses and sequence and phylogenetic analyses of the rDNA intergenic spacers show to be valuable tools for genetic studies of triatomines. This integrated approach provids evidence of genetic heterogeneity between T. rubrovaria populations from Livramento, Brazil and Salto and Río Negro, Uruguay. Furthermore, populations from Corrientes, Argentina and Santiago, Brazil appear to be isolated probably because of distances (Dujardin et al., 1998).

In Southern Brazil, T. rubrovaria has begun to invade dwellings and peri-domiciles due to anthropic factors, related to farming activities and the replacement of the original fauna and flora. The diversity of mammals may also have contributed to the emergence of larger populations of T. rubrovaria in such modified environments (Almeida et al., 2000, 2002). In rural areas of Argentina, the passive dispersion of $T$. rubrovaria to urban centres with stones used for house building has been 
reported (Bar et al., 2003). The large intraspecific variability detected may underlie the known plasticity of T. rubrovaria, making it a potential intradomiciliary invader and consequently an appropriate vector for Chagas disease transmission. Therefore, this triatomine species must be continuously monitored throughout (Bar et al., 2003; Almeida et al., 2005).

\section{ACKNOWLEDGEMENTS}

his work has been performed within the Technical Cooperation Agreement between Fiocruz (Brazil) and Universidad de Valencia (Spain). Financial support was obtained from the following Projects: PAPES 3 (Fiocruz); "Chagas Disease Intervention Activities" (CDIA-ICA4CT-2003-10049), European Commission, Brussels; and RICET No. C03/04, FIS, Spanish Ministry of Health, Madrid, Spain. D.R. Klisiowicz was on leave from the Departamento de Patologia Basica, Universidade Federal do Paraná, Centro Politécnico Curitiba, PR, Brazil. F. Panzera benefited from funding by the Conselleria de Cultura i Educació of the Valencia Government, Spain and the University of Valencia for two working stays at the Parasitology Department of Valencia. We thank Roberto Salvatella (Faculty of Medicine and PAHO, Montevideo, Uruguay) for providing specimens from Uruguay. Technical support for the authomatic sequencing provided by the DNA Sequencing Service of the University of Valencia.

\section{REFERENCES}

Almeida C.E., Vinhaes M.C., Almeida J.R., Silveira A.C. \& Costa J. Monitoring the domiciliary and peridomiciliary invasion process of Triatoma rubrovaria in the State of Rio Grande do Sul, Brazil. Memórias do Instituto Oswaldo Cruz, 2000, 95, 761-768.

Almeida C.E., Pacheco R.S., Noireau F. \& Costa J. Triatoma rubrovaria (Blanchard, 1843) (Hemiptera: Reduviidae). I: Isoenzymatic and chromatic patterns of five populations from the State of Rio Grande do Sul, Brazil. Memórias do Instituto Oswaldo Cruz, 2002, 97, 829-834.

Almeida C.E., Folly-Ramos E., Agapito-Souza R., Magno-EspeRANÇA G., PACHECO R.S. \& Costa J. Triatoma rubrovaria (Blanchard, 1843) (Hemiptera: Reduviidae: Triatominae) IV: bionomic aspects on the vector capability of nymphs. Memórias do Instituto Oswaldo Cruz, 2005, 100, 231-235.

Bar M.E., Milano A.M.E., Damborsky M.P., Oscherov E.B. \& Avalos G. Patrones de alimentación y de defecación de Triatoma rubrovaria bajo condiciones de laboratorio. Revista de la Sociedad Entomológica Argentina, 2003, 62, 107-113.

Bargues M.D., Marcilla A., Ramsey J., Dujardin J.P., Schofield C.J. \& MAS-Coma S. Nuclear rDNA-based molecular clock of the evolution of Triatominae (Hemiptera: Reduviidae), vectors of Chagas disease. Memórias do Instituto Oswaldo Cruz, 2000, 95, 567-573.
Bargues M.D., Marcilla A., Dujardin J.P. \& Mas-Coma S. Triatominae vectors of Trypanosoma cruzi: a molecular perspective based on nuclear ribosomal DNA markers. Transactions of the Royal Society of Tropical Medicine and Hygiene, 2002, 96, S159-S164.

Bargues M.D., Kuisiowicz D.R., Panzera F., Nolreau F., Marcilla A., Pérez R., Rojas M.G., O’Connor J.E., Galvao C., Jurberg J., Carcavallo R.U., Dujardin J.P. \& Mas-Coma S. Origin and phylogeography of the Chagas disease main vector Triatoma infestans based on nuclear rDNA sequences and genome size. Infection, Genetics and Evolution, 2006, 6, 46-62.

DAMBorsky M.P., BAR M.E. \& Gorla D. Life cycle and reproductive patterns of Triatoma rubrovaria (Blanchard, 1843) (Hemiptera: Reduviidae) under constant and fluctuating conditions of temperature and humidity. Revista da Sociedade Brasileira de Medicina Tropical, 2005, 38, 433-437.

Dujardin J.P., Schofield C.J. \& TibaYREnc M. Population structure of Andean Triatoma infestans: allozyme frequencies and their epidemiological relevance. Journal of Medical Entomology, 1998, 12, 20-29.

Dujardin J.P., Schofield C.J. \& Panzera F. Les Vecteurs de la maladie de Chagas. Recherches taxonomiques, biologiques et génétiques. Academie Royale des Sciences d'Outre Mer. Bruxelles, Belgique, 2000, 1-162.

LENT H. \& Wygodzinsky P. Revision of the Triatominae (Hemiptera: Reduviidae) and their significance as vectors of Chagas disease. Bulletin of the American Museum of Natural History, 1979, 163, 123-520.

Marcilla A., Bargues M.D., Ramsey J., Magallon-Gastelum E., Salazar-Schettino P.M., Abad-Franch F., Dujardin J.P., Schofield C.J. \& Mas-Coma S. The ITS-2 of the nuclear rDNA as a molecular marker for populations, species and phylogenetic relationships in Triatominae (Hemiptera: Reduviidae), vectors of Chagas disease. Molecular Phylogenetics and Evolution, 2001, 18, 136-142.

Marcilla A., Bargues M.D., Abad-Franch F., Panzera F., Carcavallo R.U., Noireau F., Galvão C., Jurberg J., Miles M., DuJARDin J.P. \& MAS-COMA S. Nuclear rDNA ITS-2 sequences reveal polyphyly of Panstrongylus species (Hemiptera: Reduviidae: Triatominae), vectors of Trypanosoma cruzi. Infection, Genetics and Evolution, 2002, 1, 225-235.

Pacheco R.S., Almeida C.E., Costa J., Klisiowicz D.R., MasCOMA S. \& BARgues M.D. RAPD analyses and rDNA intergenic spacer sequences discriminate Brazilian populations of Triatoma rubrovaria (Reduviidae: Triatominae). Annals of Tropical Medicine \& Parasitology, 2003, 97, 757-768.

Posada D. \& CRANDAll K. A. Modeltest: testing the model of DNA substitution. Bioinformatics, 1998, 14, 817-818.

Salvatella R., Rosa R., Basmadjian Y., Puime A., Calegari L., Guerrero J., Martinez M., Mendaro G., Briano D., Montero C. \& WisNivesky-COOLli C. Ecology of Triatoma rubrovaria (Hemiptera: Triatominae) in wild and peridomestic environments of Uruguay. Memórias do Instituto Oswaldo Cruz, 1995, 90, 325-328.

SwOFFORD D.L. PAUP*: Phylogenetic Analysis Using Parsimony (*and other methods). [4.0beta]. Sinauer Associates, Sunderland, MA, 2002.

Reçu le 24 janvier 2007 Accepté le 22 mai 2007 


\section{PARASITE}

Formulaire à retourner à réception de l'accord de publication.

Form to be returned when receiving the publication agreement.

\section{FRAIS TECHNIQUES / TECHNICAL COSTS}

\ Frais de publication / Publication costs:

Euro 120

$\square$ Page(s) imprimée(s) au-delà de 8 / Additional printed page(s) above 8 pages:

Euro $100 \times \ldots$.

$\square$ Reproductions en quadrichromie / Four-color reproductions:

\section{TOTAL 1 : Euro}

A réception de règlement, l'auteur correspondant recevra 25 tirés à part et la version sous format .pdf de l'article.

On receipt of payment, the correspondence author will receive 25 reprints and the .pdf offprints.

\section{TIRÉS A PART / ADDITIONAL REPRINTS}

Prix TTC, port compris, à compter du 1er janvier 2007 / Price, taxes and postage included, from January 1st, 2007

\begin{tabular}{ccccccc}
\hline \multirow{2}{*}{ Nombre/Number } & \multicolumn{2}{c}{$1-4$ pages } & \multicolumn{2}{c}{$5-8$ pages } & \multicolumn{2}{c}{$9-12$ pages } \\
\cline { 2 - 7 } & Euros & USD & Euros & USD & Euros & USD \\
\hline 50 & 215 & 245 & 225 & 265 & 265 & 310 \\
100 & 250 & 295 & 265 & 310 & 315 & 370 \\
150 & 300 & 355 & 325 & 385 & 370 & 455 \\
\hline
\end{tabular}

TOTAL 2 : Euro

TOTAL $1+2$ : Euro

Paiement joint à l'ordre de / Please find herewith the corresponding payment to PRINCEPS-PARASITE

$\square$ par carte de crédit / by credit card

Nom / Name, Date \& signature:

No/ . I....... I .. I . . ...

Date d'expiration / Ends:

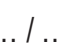

口 par virement bancaire au compte $n^{\circ} 30004$ / 00585 / 00020098545 / 59 BNP Paribas: 57, rue du Général Leclerc, F-92130 Issy-les-Moulineaux by credit transfer IBAN: FR76 30004005850002009854559 ñ BIC: BNPAFRPPBBT

$\square$ par chèque bancaire / by cheque

Bon de commande joint / Order of the laboratory enclosed

$\square$ Facture souhaitée / Invoice requested (please provide your VAT number for EC) 